\title{
Peningkatan Keterampilan Pelajar SMP Van Lith Melalui Pelatihan Dasar Desain Grafis
}

\author{
Muhammad Rusli' ${ }^{1}$, Andrew $^{2)}$, Muhammad Zhafran ${ }^{3)}$, Shella Sagita Theo"), \\ Vadly Ramadhani Halim ${ }^{5}$, Vania Gabriele Zega ${ }^{\text {6) }}$ \\ 1) Sistem Informasi, Institut Teknologi dan Bisnis Kalbis \\ Jalan Pulomas Selatan No 22, Jakarta 13210 \\ ${ }^{1)}$ Email: Muhammad.rusli@kalbis.ac.id \\ 2,3,4,5,6) Manajemen, , Institut Teknologi dan Bisnis Kalbis \\ Jalan Pulomas Selatan No 22, Jakarta 13210 \\ ${ }^{2)}$ Email:andrewsusanto1999@gmail.com \\ 3)Email: mzhafran111@gmail.com \\ 4) Email: shellasagitaa@gmail.com \\ 5) Email: vadlyramadhani@gmail.com \\ 6) Email: vaniagabrielezega@gmail.com
}

\begin{abstract}
This training activity was carried out in collaboration with Van Lith Junior High School as a partner. The primary graphic design training program is implemented because many Van Lith Junior High School graduates still do not know graphic design basics. This training method is carried out by providing material and followed by an evaluation of the participants' results. This training is carried out so that students' abilities can directly understand the basics of graphic design. The results of the implementation of this community service activity are a provision for students in the future. This implementation is carried out online because it coincides with the Covid-19 pandemic.
\end{abstract}

Keywords: community service, graphic design, online, training

\begin{abstract}
Abstrak: Kegiatan pelatihan ini dilaksanakan bekerjasama dengan SMP Van Lith sebagai mitra. Program pelatihan dasar desain grafis dilaksanakan karena masih banyak lulusan SMP Van Lith yang masih belum mengetahui secara jelas dasar desain grafis. Metode pelatihan ini dilakukan dengan pemberian materi serta dilanjutkan dengan evaluasi dari hasil peserta. Pelatihan ini dilakukan agar kemampuan siswa dapat secara langsung mengerti dasar desain grafis. Hasil dari pelaksanaan kegiatan pengabdian kepada masyarakat ini sebagai bekal siswa siswa dikemudian hari. Pelaksanaan ini dilakukan secara daring karena bertepan dengan masa pandemi Covid 19.
\end{abstract}

Kata Kunci: daring, desain grafis, pelatihan, pengabdian kepada masyarakat

\section{PENDAHULUAN}

Video merupakan salah satu produk dari penggunaan teknologi yang kreatif. Video didapatkan dengan cara merekam video, kemudian diolah berupa suara atau sound dan gambar bergerak di komputer, menggunakan alat peraga dan kadang bentuk arsitektur. Media video merupakan salah satu media komunikasi yang paling mendominasi dalam Perkembangan Teknologi di Indonesia akhirakhir ini. Selain itu perkembangan media sharing video yang menunjang terdistribusinya sebuah karya video kreatif, juga semakin banyak digunakan oleh masyarakat luas. Hal ini membuka peluang bagi setiap individu, baik dari kalangan pelajar maupun umum untuk berlomba lomba berkreasi dan memproduksi karya videonya untuk keperluan pengembangan diri, promosi, maupun usaha yang lainnya.
Program pelatihan Pembelajaran Dasar Desain Grafis dilaksanakan karena masih banyak para pelajar SMP Van Lith yang tidak mengerti menggunakannya. Keterampilan ini akan sangat berguna bagi pelajar SMP Van Lith yang ingin berwirausaha di bidang multimedia, seperti video shooting, produksi film, start up, dan lain-lain yang terkendala kemampuan yang dimiliki. (Lith, 2020)

\section{METODE PELAKSANAAN}

PKM Peningkatan Keterampilan Pelajar SMP Van Lith Melalui Pelatihan Dasar Desain Grafis merupakan suatu bentuk pengabdian dari mahasiswa dan mahasiswi Kalbis Institute kepada masyarakat, di masa pandemi Covid-19. Dengan memberikan edukasi secara virtual mengenai Design Grafis, para pelajar di tingkat SMP agar memiliki kemampuan 
design. Mahasiswa yang terlibat adalah sekelompok mahasiswa Kalbis Institute yang sedang mengambil mata kuliah Kalbis Peduli..

PKM (Pengabdian Kepada Masyarakat) merupakan salah satu program kepedulian kepada masyarakat yang dilakukan oleh mahasiswa, yang dinaungi oleh Kalbis Institute. Sehingga segala sesuatu yang kami lakukan dalam kegiatan ini adalah resmi dan akan kami pertanggung jawabkan sebagai anggota dari Lembaga Kalbis Institute.

Dengan keterlibatan kami dalam kegiatan ini, diharapkan dapat memberikan pengalaman ilmu pengetahuan, teknologi, dan kepedulian agar dapat memecahkan masalah yang ada di lingkungan tersebut, baik secara kelompok maupun individual. Proyek ini juga diharapkan mampu meningkatkan potensi masyarakat walaupun dalam situasi yang sulit seperti saat ini.

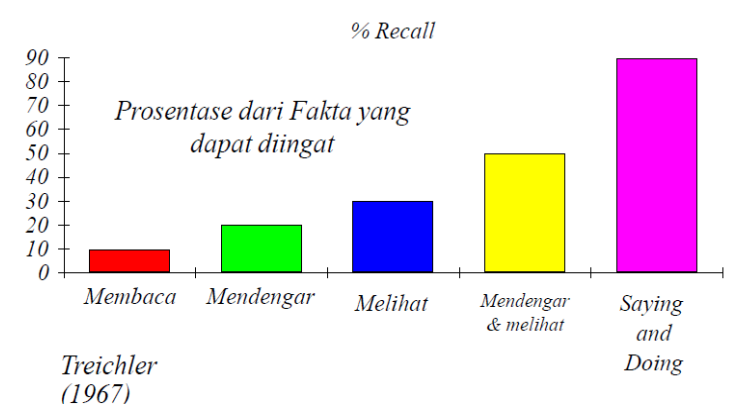

Gambar 1 Grafik hasil penelitian Treicher

Tim Pengabdian Kepada Masyarakat memberikan pelatihan dasar desain grafis kepada mitra hal itu bedasarkan tim mengamati di era digital saat ini, manusia tidak lepas dari teknologi gadget yang salah satunya yang digemari generasi saat ini, yaitu berselancar di dunia maya. Semakin berkembangnya zaman, manusia semakin besar intensitas nya dalam penggunaan media sosial bahkan hingga semua bidang dalam kehidupan membutuhkan desain grafis. Manfaat desain grafis dapat kita rasakan secara nyata di kehidupan sehari-hari. Desain grafis sendiri sangat lekat dalam memberikan makna, persepsi, pencitraan, dan juga komunikasi. Desain grafis memudahkan dalam bertukar informasi, membuat suatu informasi menjadi lebih menarik dan lebih nyaman secara visual. Karena itulah desain grafis menjadi salah satu bidang yang diminati oleh generasi muda saat ini. Yang diperlukan adalah kreativitas dan tentu saja ilmu-ilmu dasar untuk mengenali prinsip dasar dalam desain, prisip dasar komunikasi, menggunakan aplikasi desain grafis, sehingga tercipta original karya. Dalam Gambar 1 dipaparkan juga mengapa perlu mempelajari desain grafis, salah satu nya karena desain grafis terdiri dari berbagai metode dilakukan/ dikombinasikan dengan menggunakan symbol,foto, gambar, teks untuk menciptakan mengkomunikasian ide/pesan se-efektif mungkin. (Jessica, 2020).

$$
\text { Dalam program Pengabdian Kepada }
$$

Masyarakat (PKM) yang kami lakukan, kami mendasari dengan memakai salah satu teori dari cabang Imu Komunikasi, yaitu Teori Konstruktivisme oleh Jesse Dellia. Konstruktivisme adalah sebuah teori yang dikembangkan oleh Jesse Delia dan koleganya, memiliki pengaruh kuat pada bidang komunikasi. Teori tersebut mengatakan bahwa individu menafsirkan dan bertindak menurut kategori konseptual yang ada di dalam pikiran. Realitas tidak menghadirkan dirinya dalam bentuk kasar, tetapi harus disaring melalui cara seseorang melihat sesuatu (Littlejohn \& Foss, 2009 ).

Konstruktivisme mengenali bahwa gagasan memiliki asal mula sosial dan dipelajari melalui interaksi dengan orang lain. Selanjutnya, budaya terlihat sangat penting dalam menentukan makna dari sebuah kejadian. Kebudayaan dapat mempengaruhi cara-cara tujuan komunikasi ditetapkan, bagaimana tujuan dicapai, seperti jenis-jenis gagasan yang digunakan dalam skema kognitif. Dalam hal ini, kami berusaha menyebarkan pesan kepada orang lain untuk selalu berempati kepada orang sekitar kita. Dalam hal ini, kami memakai 3 (tiga) metode pelaksanaan, yaitu: metode sebelum pelaksanaan, metode pelaksanaan saat PKM, dan Metode setelah dilaksanakannya PKM.

\section{A. Metode Sebelum Pelaksanaan}

Dalam metode ini, salah satu dari anggota kelompok kami, Shella Sagita Theo melakukan pendekatan dengan mitra baik dengan beberapa Bapak/Ibu Guru SMP Van Lith maupun siswa/i SMP Van Lith untuk mensurvey aktivitas keseharian siswa/i, jadwal kegiatan pembelajaran siswa/i, jadwal mengajar bapak/ibu guru, dan juga mencari tahu kebutuhan/ pelatihan seperti apa yang diperlukan mitra hingga sejauh mana pengetahuan mitra mengenai desain grafis.

Dalam metode ini kami lebih memfokuskan untuk saling bertukar pikiran satu sama lain (tim dengan mitra) melalui chatting dan audio call lewatfitur dalam Whatsapp. Hal itu dilakukan oleh perwakilan salah satu anggota kelompok kami, Shella Sagita Theo. Dalam metode ini kami bisa mengetahui lebih banyak mengenai aktivitas baik guru maupun siswa/i dalam pembelajaran jarak jauh yang dilakukan SMP Van Lith. Tak hanya itu, kami juga mempresentasikan 
perencanaan acara PKM kami pada Bapak Cahyo selaku Wakasek (Wakil Kesiswaan) SMP Van Lith, Bapak Hendro yang membantu dalam mengatur jadwal bapak/ibu guru dan waktu kegiatan belajar mengajar, dan ditemani pula dengan Bapak Dayson, selaku Guru pelajaran Seni Budaya SMP Van Lith untuk mendapatkan persetujuan dan perizinan dalam membantu berjalannya kegiatan PKM nantinya. Secara internal, Tim juga sering melakukan Group Discussion melalui video conference dan audio call untuk berdiskusi mempersiapkan kegiatan PKM, seperti adanya Gladi Kotor dan Bersih yang kami lakukan di sehari kurang dari hari H PKM. Hal itu membuat kami mengetahui pembagian masingmasing tugas dan materi presentasi di bagain mana pada masing-masing kami dalam pelaksanaan PKM. Kami juga berlatih dalam mempresentasikan materi dengan Metode Pecakucha (20 detik/slide) sehingga kami bisa efektif dalam waktu presentasi, setelah itu kami berdiskusi jalannya kegiatan PKM secara teknis, mengetahui pula pembagian letak bagian masing-masing tanggung jawab anggota tim.

\section{B. Metode Pelaksanaan Saat PKM}

Tim akan melakukan presentasi online dengan metode Pecha Kucha (20 detik/slide). Dalam melaksanakan presentasi, masing- masing kami akan diberi waktu $\pm 20 \mathrm{detik} /$ slide dalam menjelaskan isi presentasi yang telah dibuat untuk presentasi kepada peserta PKM/ mitra. Apabila waktu sudah habis, anggota tim yang bertugas dibagian Slide Show akan mengganti slide berikutnya. Dapat dilihat pada Gambar 2.

Dalam pelaksanaan PKM, baik pada sesi awal, presentasi, hingga akhir, kami masing-masing menyalakan kamera kami (ON Camera). Hal itu diharapkan, diantara kami dengan mitra bisa saling mengenal. Kami juga mengimbau peserta yang mengikuti menyalakan kamera nya sehingga suasana PKM terasa dan bisa berjalan interaktif di antara tim dengan peserta. Setelah itu, dilanjutkan dengan sesi QnA yaitu Tanya Jawab. Hal itu kami lakukan agar dapat memberikan output maksimal pada peserta untuk memahami betul dasar desain grafis, sehingga dari setiap kebingungan yang masih ada pada peserta dapat ditanyakan lewat memberikan kami pertanyaan, lalu kami memberikan jawaban yang sekiranya dapat menjawab kebingungan peserta. Di antara anggota tim juga saling membantu menjawab dan menambahkan dari pertanyaan yang muncul, seperti dari maksud awal kami berupa target Iptek yang ditransfer adalah dalam bentuk berbagi ilmu dan meningkatkan rasa

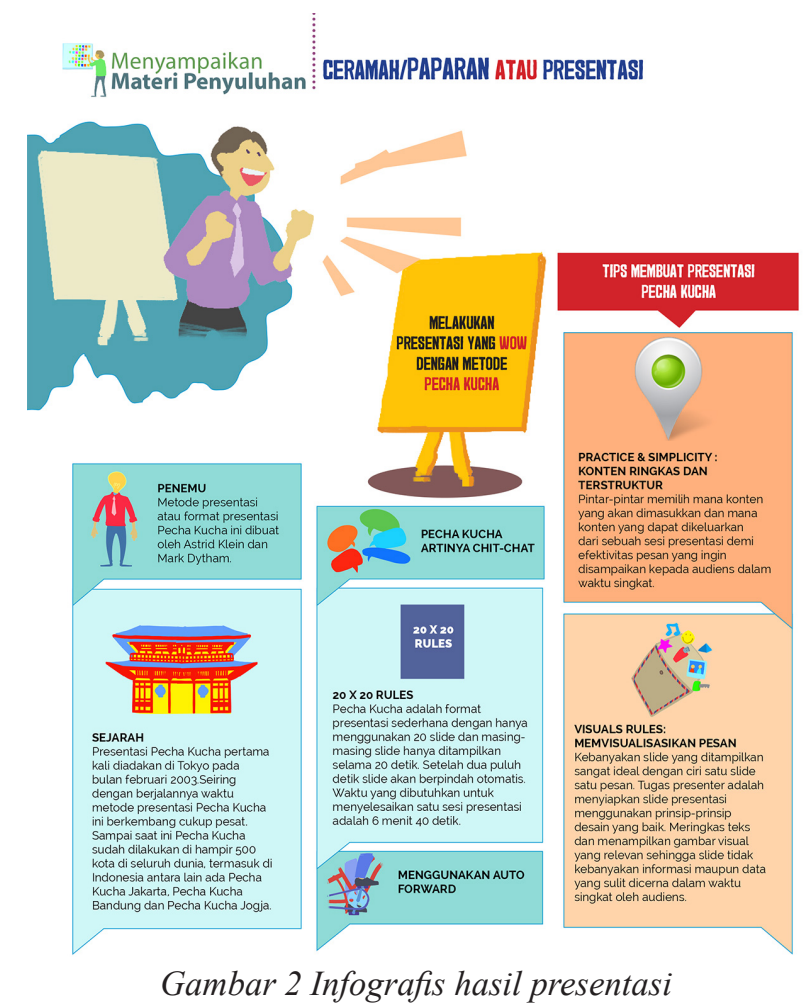

kepedulian dengan mitra sehingga mitra memperoleh wawasan penuh dan pengetahuan mendalam yang detil akan dasar desain grafis.

\section{Metode Setelah dilaksanakannya kegiatan PKM}

Dalam hal ini, kami menyediakan bantuan lainnya seperti memberikan soft copy materi yang dipresentasikan tersebut untuk bahan pembelajaran peserta dikemudian hari, lalu apabila ada pertanyaan yang masih dibingungkan, peserta bisa tanyakan lebih lanjut setelah PKM ini berakhir karena kami menyadari waktu sesi tanya jawab sangat terbatas.

\section{HASIL DAN PEMBAHASAN}

Tim Pengabdian Kepada Masyarakat melaksanakan kegiatan secara virtual di rumah masing-masing dengan sebelumnya kami mempersiapkan diri, bahan materi yang akan disampaikan, dan perlengkapan dan peralatan yang mendukung keberlangsungan acara. Mitra kami adalah Siswa-siswi dari SMP Van Lith. Seperti pada Gambar 3.

Kegiatan Pengabdian berlangsung pada tanggal 12 Desember 2020, pada jam 09:00 WIB pagi melalui video conference Google Meet. Pengabdian ini sebagai bentuk tanggung jawab kami sebagai mahasiswa-mahasiswi melaksanakan kegiatan Tri Dharma Perguruan Tinggi. Dalam pelaksanaan pengabdian ini, kami berlima sebagai tim Pengabdian Kepada Masyarakat berkoordinasi bersama dengan 


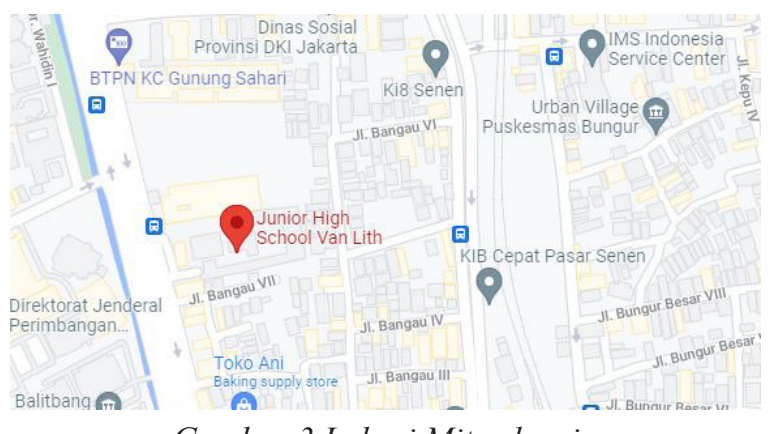

Gambar 3 Lokasi Mitra kami

tujuan untuk melatih diri dalam berjalannya kegiatan di masyarakat. Adapula kami dibantu oleh Bapak dan Ibu Guru SMP Van Lith yang telah mendukung kami dengan membantu membagikan informasi mengenai acara kegiatan ke grup-grup tiap kelas di SMP Van Lith. Judul kegiatan ini adalah "Peningkatan Keterampilan Siswa SMP Van Lith Melalui Pelatihan Dasar Desain Grafis". Berikut ini rincian kegiatan yang kami laksanakan, seperti pada Gambar 4 dan Gambar 5..

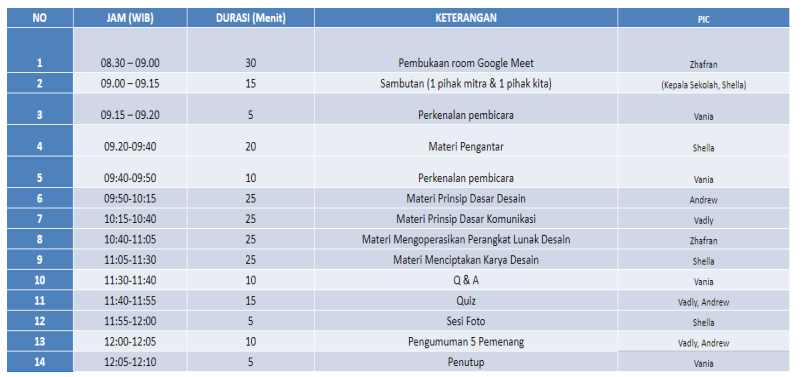

Gambar 4 Rundown Acara

\begin{tabular}{|l||l|}
\hline & \multicolumn{1}{||}{ Judul Unit } \\
\hline 1 & Mengaplikasikan prinsip dasar desain \\
\hline 2 & Menerapkan prinsip dasar komunikasi \\
\hline 3 & Menerapkan design brief \\
\hline 4 & Mengoperasikan perangkat lunak desain \\
\hline 5 & Menciptakan karya desain \\
\hline
\end{tabular}

Gambar 5 Materi presentasi

Materi yang kami susun mereferensikan dari BPPTIK (Balai Pelatihan dan Pengembangan Teknologi Informasi dan Komunikasi).

Kami mendesain poster untuk acara yang kami laksanakan untuk diberikan kepada Bapak/Ibu Guru SMP Van Lith, agar nantinya beliau informasikan kepada anak-anak lewat grup disetiap kelasnya. Lalu kami juga membuat 2 Google Form, yang pertama untuk registrasi peserta dan kedua untuk mengukur kepuasan dari acara PKM dan penjelasan materi yang telah kami sampaikan. Seperti pada Gambar 6 dan Gambar 7.

Tak hanya Tim menitipkan poster, kami juga telah menyusun kata-kata yang diperlukan untuk di broadcast kan yang berisi pesan acara PKM (Pengabdian Kepada Masyakarat) untuk dibagikan di group kelas anak-anak SMP Van Lith dan group Bapak/Ibu Guru. Pelaksanaan PKM seperti pada Gambar 8 dan Gambar 9.

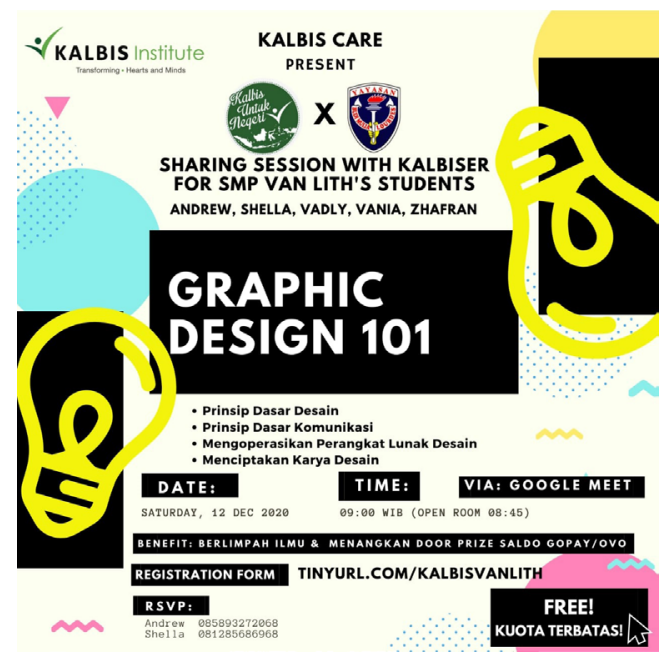

Gambar 6 Desain Feed yang kami buat untuk disebarluaskan kepada mitra

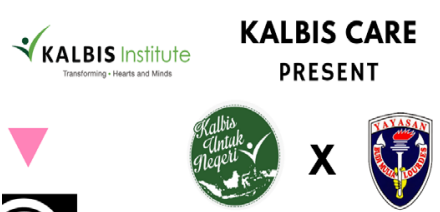

SHARING SESSION WITH KALBISER FOR SMP VAN LITH'S STUDENTS

ANDREW, SHELLA, VADLY, VANIA, ZHAFRAN

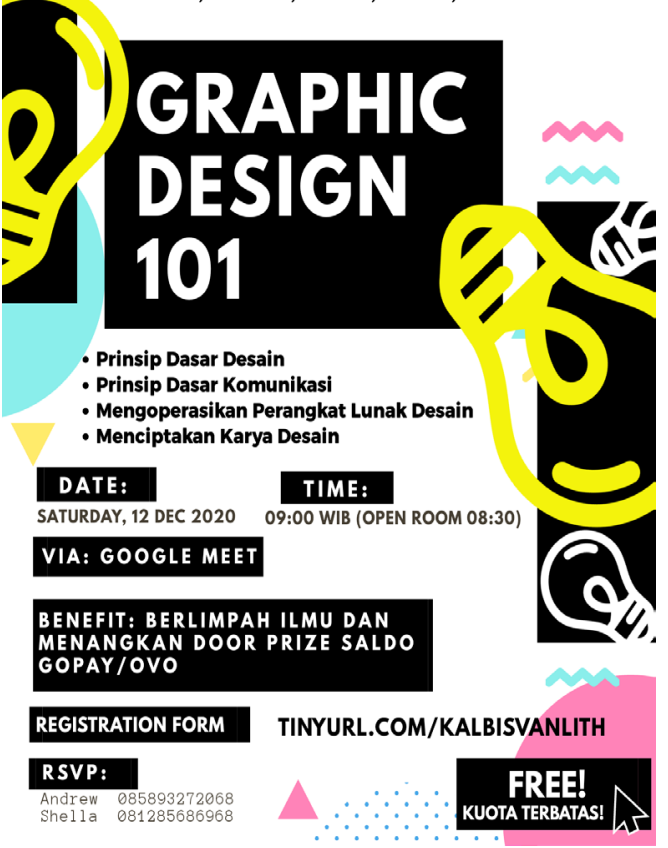

Gambar 7 Desain Story yang kami buat untuk disebarluaskan kepada mitra

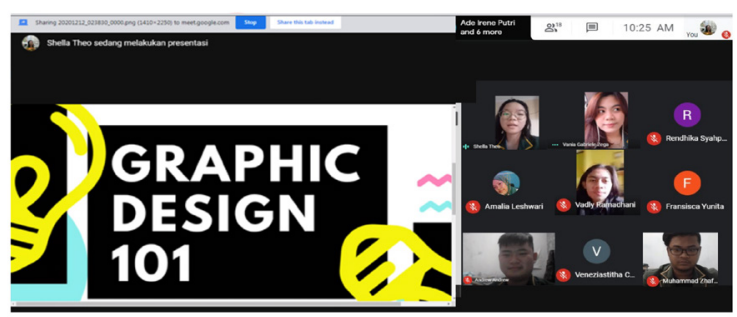

Gambar 9 Dokumentasi pelaksanaan PKM 


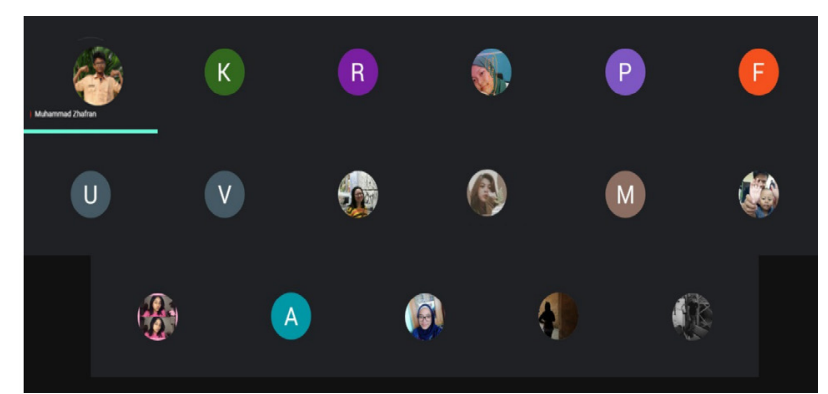

Gambar 10 Dokumentasi dengan peserta yang mengikuti kegiatan PKM

Adanya sesi foto bertanya setelah QnA untuk menutup kegiatan PKM kami berupa pelatihan Dasar Desain Grafis. Penutupan dilakukan dengan closing statement satu persatu dari kami kepada peserta pelatihan. seperti pada Gambar 10.

\section{SIMPULAN}

Pembelajaran yang kami berikan kepada SMP Van Lith berupa video dan pemberian contoh secara langsung lewat g-meet tentang dasar desain grafis. Kelebihan dari video pembelajaran kami melalui g-meet ialah lebih mudah mengajarkan walaupun jarak sangat jauh tetapi kekurangannya ialah banyak siswa yang telat masuk dan pengulangan dari awal, maka dari itu kami menunggu lengkap para siswa SMP Van Lith.

\section{DAFTAR RUJUKAN}

Jessica, C. (2020, 12 29). glints. Diambil kembali dari Menggemari Seni? Kenali Dunia Desain Grafis dan Lingkup Kerjanya: https://glints.com/id/lowongan/apaitu-desain-grafis/\#.YTByb05R3IV

Lith, S. V. (2020, 12 10). SMP Van Lith. Diambil kembali dari SMP Van Lith: http://smpvanlith-bm91.mysch.id

Littlejohn, S. W., \& Foss, K. A. (2009 ). Teori Komunikasi. edisi 9. Jakarta: Salemba Humanika. 